Recibido: junio de 2015

Aprobado: agosto de 2015

DOI:

http://dx.doi.org/I0.15332/rev.m.vI2il.1924

\section{PÕNS ET SUMMA: EL TEMPLO EXPIATORIO DE GUADALAJARA COMO SÍNTESIS ARQUITECTÓNICA E HISTÓRICA MEXICANA*}

José Manuel Falcón Meraz** - Instituto Tecnológico y de Estudios Superiores de Occidente (ITESO), México Carlos Alberto Domenzain Rodríguez ${ }^{* * *}$ - Instituto Tecnológico y de Estudios Superiores de Monterrey (ITESM), México

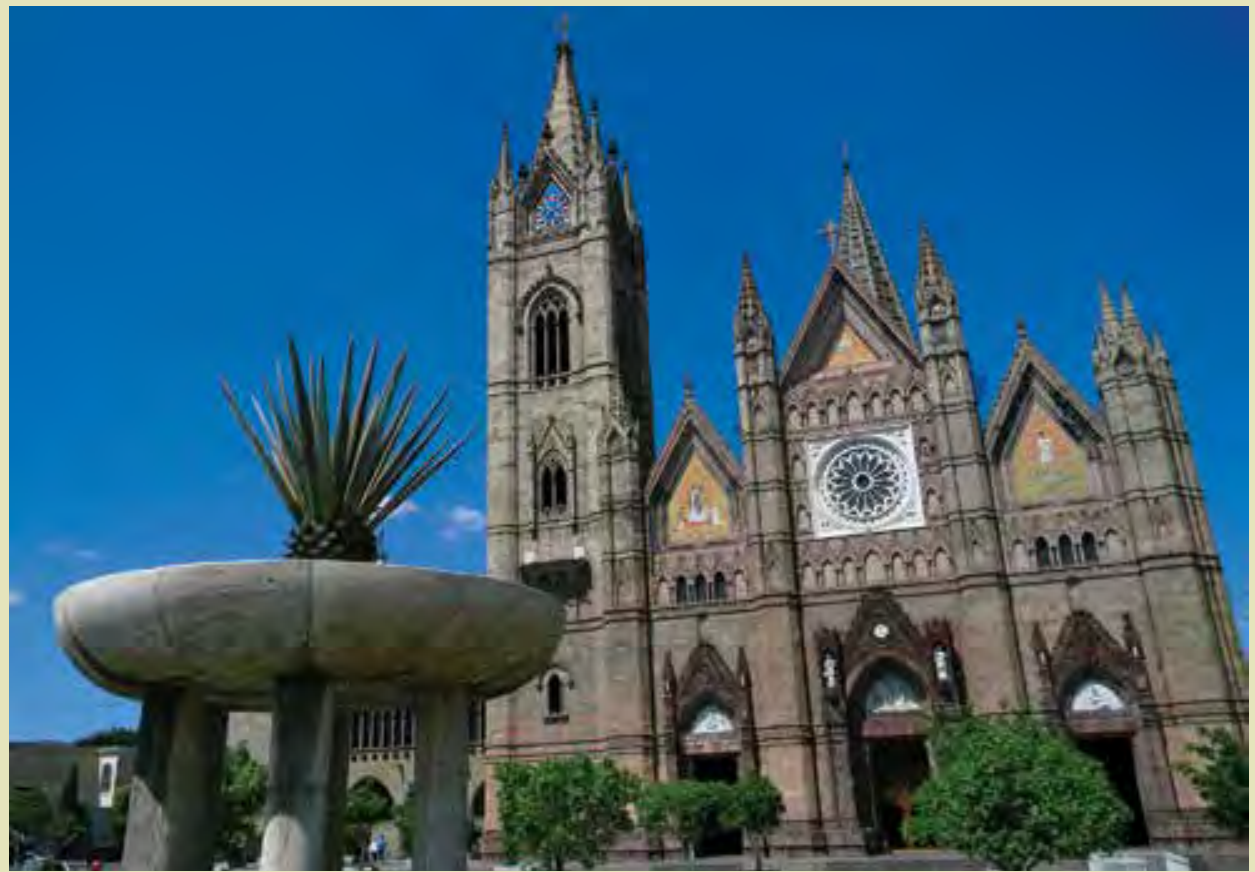

\section{RESUMEN}

El Templo Expiatorio de Guadalajara, México (1897-1972) es un símbolo de la segunda ciudad más poblada -y la más religiosa- del país. Su construcción ecléctica, obra de diferentes autores, es resultado directo de procesos políticos y culturales convulsos que, a su vez, han actuado como un puente ideológico nacional único. El templo es un símbolo de la transformación de un ideal religioso en una apropiación cívica; ha sido punto de contacto y de "cruce" convirtiéndose en un lugar de contacto social, interacción y aprovechamiento del espacio público. Su función como puente, surge de condiciones que van desde el planteamiento de una construcción monumental como justificación ideológica religiosa, hasta su papel de hito urbano, lugar de encuentro y parte de la memoria histórica de la ciudad. Hoy, este espacio es un catalizador de lo antiguo y lo moderno, elevándose como una Summa Mexicana, inseparable por su misma condición, de la evolución de la ciudad y sus habitantes.

\section{PALABRAS CLAVE}

Arquitectura mexicana, arquitectura religiosa, eclecticismo, patrimonio, neogótico. 


\section{PÕNS ET SUMMA: THE EXPIATORY TEMPLE OF GUADALAJARA AS AN ARCHITECTURAL AND HISTORICAL MEXICAN SYNTHESIS}

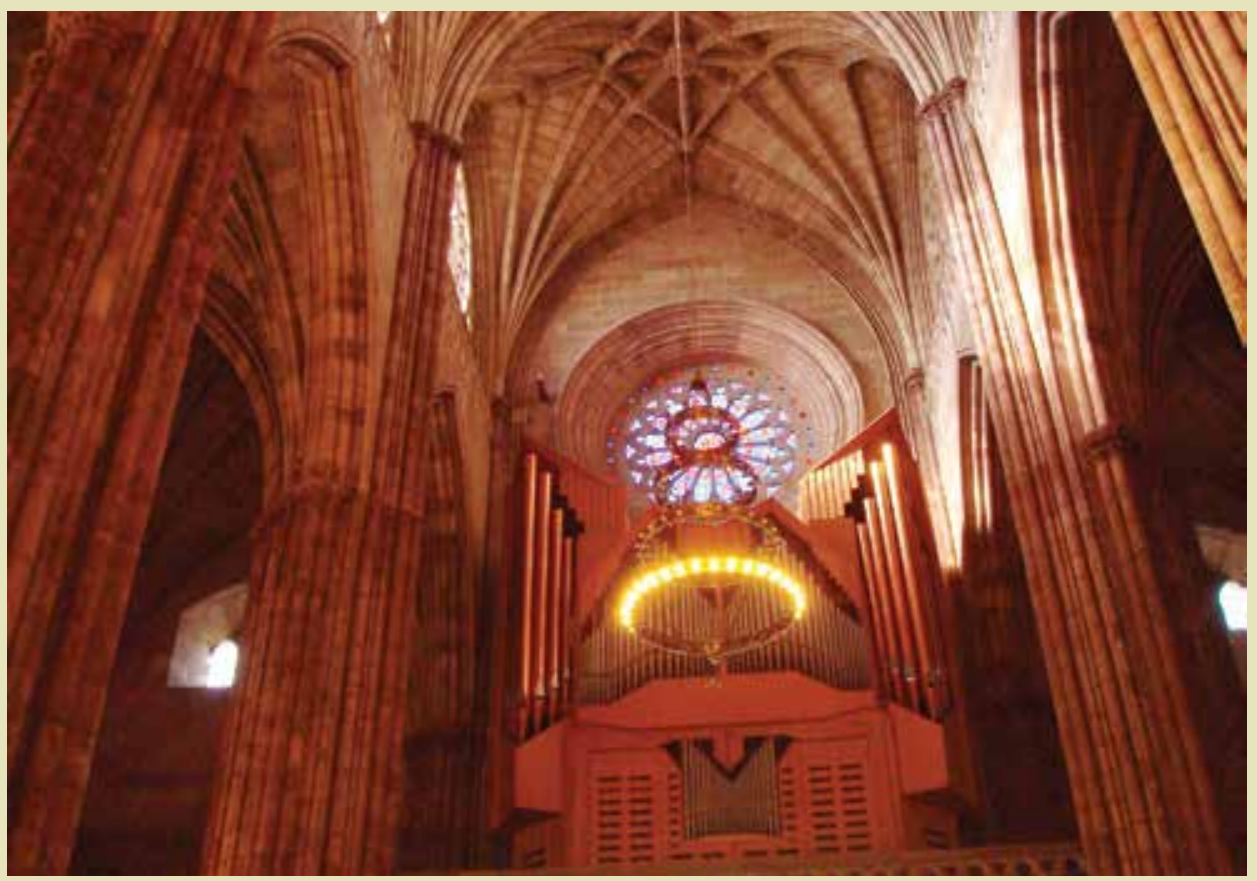

Detalle interior del Templo Expiatorio de Guadalajara.

\section{ABSTRACT}

The Guadalajara's Expiatory Temple is a symbol of the second largest city of Mexico -and the most religious of the country-. Its eclectic architecture, designed by different authors, has been a result of turbulent political and cultural processes which, at the same time, have acted as a singular ideological bridge. The temple is a symbol of the transformation of a religious ideal in a civic ownership, it has been a point of contact and a "crossover", becoming a place of social contact, interaction and public space. Its function as a bridge, arises from its conditions ranging from its role as a monumental building with a religious ideological justification, to its role as an urban landmark, meeting place and part of the historical memory of the city. Nowadays, this monumental religious space shines as a catalyst of the old and the new, rising like a Mexican Summa, inseparable from its condition, and from the evolution of the city and its inhabitants.

\section{PALABRAS CLAVE}

Mexican architecture, religious architecture, eclecticism, heritage, neogothic. 


\section{INTRODUCCIÓN: UN CONTEXTO ÚNICO}

Las ciudades son catalizadores de ideas, expresiones y pensamientos de una colectividad que se transforma continuamente. Esta transformación se produce con base en motivos complejos que van desde el crecimiento o decrecimiento de su población hasta la coexistencia de identidades sociales particulares, razones políticas y manifestaciones culturales. Las ciudades son una manifestación clara del devenir del espíritu en el tiempo (Hurtado, 20l0).

La ciudad de Guadalajara, representativa del Occidente de México, no escapa a las dinámicas de la evolución temporal. Con 83,934 habitantes en los últimos años del siglo XIX (Secretaría de Economía, 1956), es ahora una Zona Metropolitana constituida por ocho municipios y 4.5 millones de habitantes, que demuestran un interés creciente por la manera de vivirla, por sus espacios públicos y su potencial para convertirse en un referente en una época en que la ciudad depende ya de sí misma en su oferta y sus contenidos. Para Guadalajara, sus monumentos y los espacios que los rodean son un referente ineludible en la construcción de lugares de encuentro que antes no eran; tales son representación de la transformación espacial e ideológica de la urbe.

El Templo Expiatorio del Sagrado Corazón de la ciudad de Guadalajara (I897-1972) es un monumento que constituye un "puente"' con doble significado: primero, la construcción religiosa en sí, que después de un proceso de 70 años, es un reflejo del cambio existente en los estilos arquitectónicos y de las ideologías de las que se alimentó su diseño como se puede observar en la Figura I.

Figura I. Templo Expiatorio de Guadalajara, fachada oriente y plaza.

Fuente: José Manuel Falcón Meraz, 2015.

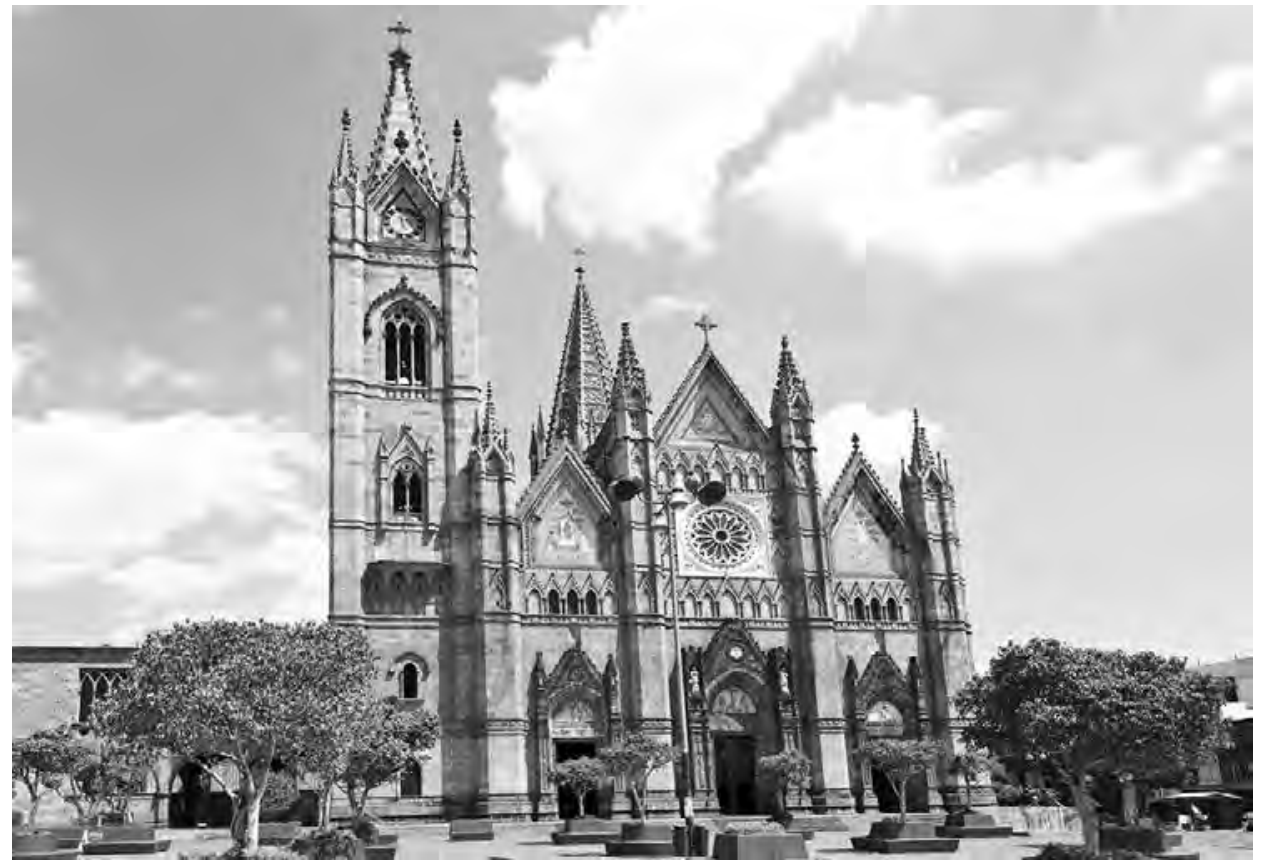

I Es importante recurrir al significado etimológico de 'puente'. Gregory Nagy (2013) establece que esta etimología parte de la palabra pontos, que muestra las siguientes relaciones con sus símiles en leguajes indo-europeos además del griego. Por ejemplo: del indio pánthãh, 'cruzar', desde un punto específico hacia otro: este 'cruzar' es tanto peligroso como sacralizante y, del latín, põns (genitivo pontis), 'puente'. De gran relevancia es el reporte de Varro (De Lingua Latina, 5.83) sobre un famoso puente, el Pôns Sublicius, que se extendía sobre el río Tíber en Roma: el prototipo de este puente fue construido y mantenido ritualmente por el prototipo del gran sacerdote romano, el pontifex maximus. La palabra latina ponti-fex quiere decir, etimológicamente, 'aquel que realiza el cruzar' o 'aquel que cruza'.

Estas acepciones son fundamentales para comprender el papel del Templo Expiatorio en el contexto local como una representación material del cruzar diversos estilos y épocas arquitectónicas y del cruzar distintas necesidades simbólicas que van desde la promoción de religiosidad católica al laicismo de los espacios cívicos de encuentro. 
Segundo, la edificación como hito representante de la transformación de un ideal religioso en una apropiación cívica haciéndolo referente local de contacto social, interacción y aprovechamiento del espacio público. La función del edificio como puente, se relaciona con la sucesión de diversas condiciones históricas que van desde la necesidad de plantear una construcción monumental como justificación ideológica religiosa, hasta la constitución simbólica como hito urbano, lugar de encuentro y parte de la memoria histórica de la ciudad.

Los conceptos de puente y summa sintetizan el despliegue arquitectónico del Templo Expiatorio. Ambos se relacionan con el misticismo judeocristiano: uno a través de la construcción de caminos hacia la inmortalidad-divinidad y, el otro, a través de la superposición de comentarios eruditos sobre las causas y efectos del dios católico. El puente es utilizado por Heidegger como una construcción que liga los elementos terrenales tanto como los espirituales. La summa, parte de la escolástica medieval, indica la compresión de diversos textos reunidos con un afán de discernimiento teológico. La summa, en su sentido más amplio, "se refiere al resultado de una agregación. Se trata entonces de acumular la totalidad de los objetos transmitidos sobre una cuestión en la tradición escolar" (Celada, 200I, p.16).

La construcción del Templo Expiatorio del Sagrado Corazón manifiesta esta doble acepción: su origen se basa tanto en el deseo de responder a una sociedad conservadora siempre deseosa de expresar su religiosidad, como en la elevación espiritual a través del sacrificio y la piedad que la comunidad ofrece como ejemplo físico a través de la edificación. Es también, una serie acumulativa de estilos arquitectónicos que representan una secuencia que va desde el eclecticismo hasta el modernismo regional de la Escuela Tapatía de Arquitectura y un ejemplo de las convulsiones históricas a la que se vio sometida la obra. De esta manera, el Expiatorio funciona como un puente entre la evolución regional y una summa que codifica la evolución de Guadalajara, ciudad y ciudadanos.

Así pues, ante la información escasa y fragmentada -concentrada en breves escritos recopilatorios de arquitectura religiosa mexicana, con fines de difusión turística-, este documento desarrolla y destaca la historia del Templo Expiatorio como un punto de contacto y de 'cruce', singular, de distintos momentos de definición arquitectónica sujeta a necesidades simbólicas mutables. Junto con estos momentos, se traza para el lugar, la existencia de una realidad pasada y una realidad presente que lo ha integrado finalmente al imaginario urbano.

\section{GOBIERNO Y RELIGIÓN: LA ARQUITECTURA DE IMPORTACIÓN COMO SÍMBOLO DE PROGRESO}

Los estilos derivados de la École des Beaux Arts de París (Escuela de Bellas Artes) constituyeron la influencia fundamental en la arquitectura mexicana durante las últimas décadas del siglo XIX e inicios del siglo XX. Este tipo de arquitectura, categorizada por Enrique de Anda como parte de un tercer período de arquitectura mexicana e inscrito dentro del marco del diseño academicista, comprende el intervalo de años que va de 1877 a 1910 . Su esencia se basa en el "propósito de halagar estéticamente a la nueva 'aristocracia' mexicana, al mismo tiempo que difunde mediante la arquitectura y la pintura la ideología del estado porfirista" (De Anda, 2008, p. I50). Con la idea de "progreso", establecida como máxima a seguir, las edificaciones, monumentos y construcciones durante la dictadura de Porfirio Díaz (1876-19II) se sintetizan en el término "eclecticismo arquitectónico". 
Figura 2. Palacio de Correos de la Ciudad

de México. Interior: vestíbulo principal y

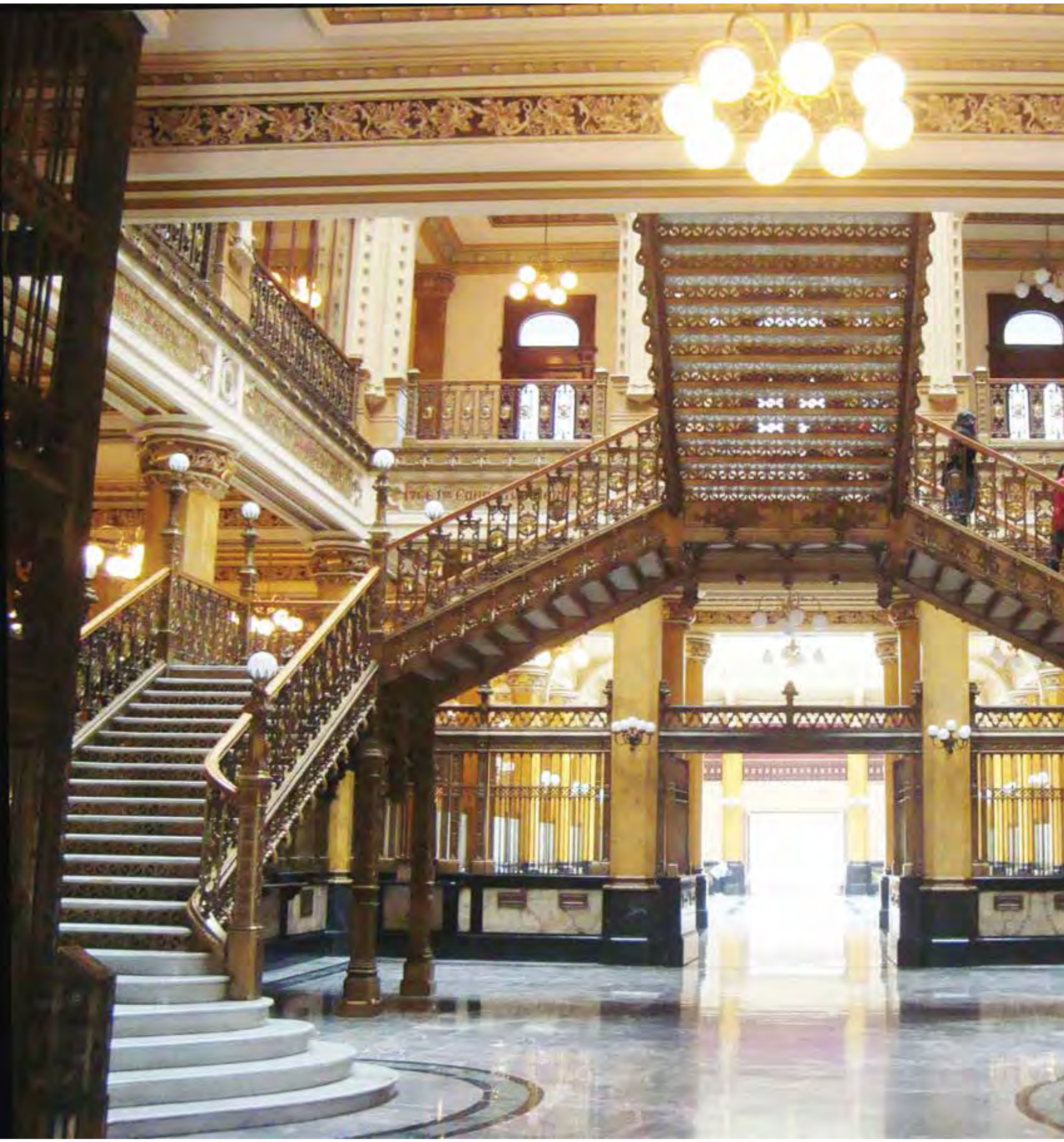




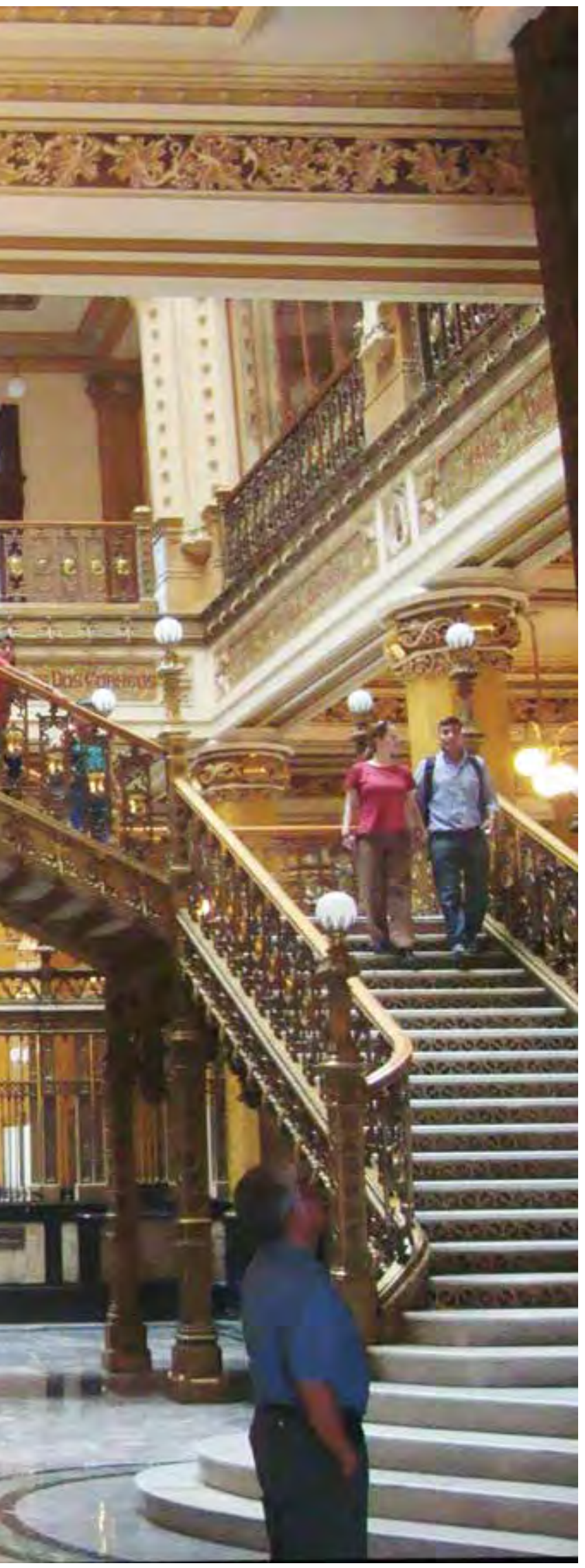

La época Porfirista dio lugar a un 'estado de bienestar' que permitió el desarrollo de proyectos que requerían una gran inversión².

El periodo porfiriano per-
mitió a los inversionistas la
formulación de proyectos
de construcción de enorme
amplitud y considerable costo
económico, siendo el sector
privado el primero que inició la
etapa constructiva del periodo,
seguido poco tiempo después
por el estado mismo. (De
Anda, 2008, p.I5I)

El resultado de dichas inversiones fueron construcciones que ejemplifican el logro de esta época: edificios como el Palacio de Correos (1902, Adamo Boari), cuyo vestíbulo puede apreciarse en la Figura 2, el Palacio Legislativo (1910, Émile Bénard), el Banco Agrícola e Hipotecario (I 904-1905, Federico y Nicolás Mariscal) y el edificio de Ferrocarriles (1905-1907, Isidro Días Lombardo).

A la aplicación de sistemas estructurales basados en la utilización de vigas y columnas de acero, se integró al uso de acabados como mármoles, granitos, bronces y vidrios. La coexistencia de un esqueleto que explotaba las posibilidades del acero, ejemplificadas en extensos claros y que liberaron a los muros y techos de su anterior cualidad estructural, junto con la ornamentación y decoración de los acabados "dieron lugar a los más diversos panoramas estilísticos, desde los manieristas clásicos [...] hasta los góticos venecianos" (De Anda, 2008, p.15I).

Las tendencias establecidas por la Escuela de Bellas Artes de París y la decisión de la Academia de San Carlos de México (Escuela Nacional de Bellas Artes desde 1867) influenciaron a los profesionales locales dedicados al diseño, la construcción y a la

2 Aunque la idea de "estado de bienestar" es relativa debido a la represión social y a la segregación y discriminación sufridas por aquellos que vivían en la pobreza o pertenecían a etnias y grupos indígenas, en este texto se presenta, únicamente, como sinónimo de prosperidad económica. 
Figura 3. Palacio de Bellas Artes de la Ciudad de México inauguración en 1934, diseño y proyecto de Adamo Boari.

Fuente: Recuperado de https:// pbaclaustrodesorjuana.wordpress.com enseñanza de estas disciplinas. A esto se sumó una participación directa de arquitectos extranjeros como los franceses Paul Dubois y Maxim Roisin y, el italiano, Adamo Boari. El ejemplo contundente de esta época es el Palacio de Bellas Artes (1904-1934), como lo muestra la Figura 3, ubicado en el Centro histórico de la Ciudad de México, diseñado por Boari que "con su recargado exotismo historicista ha resultado al paso del tiempo el edificio simbólico de la dictadura” (De Anda, 2008, p. 162).

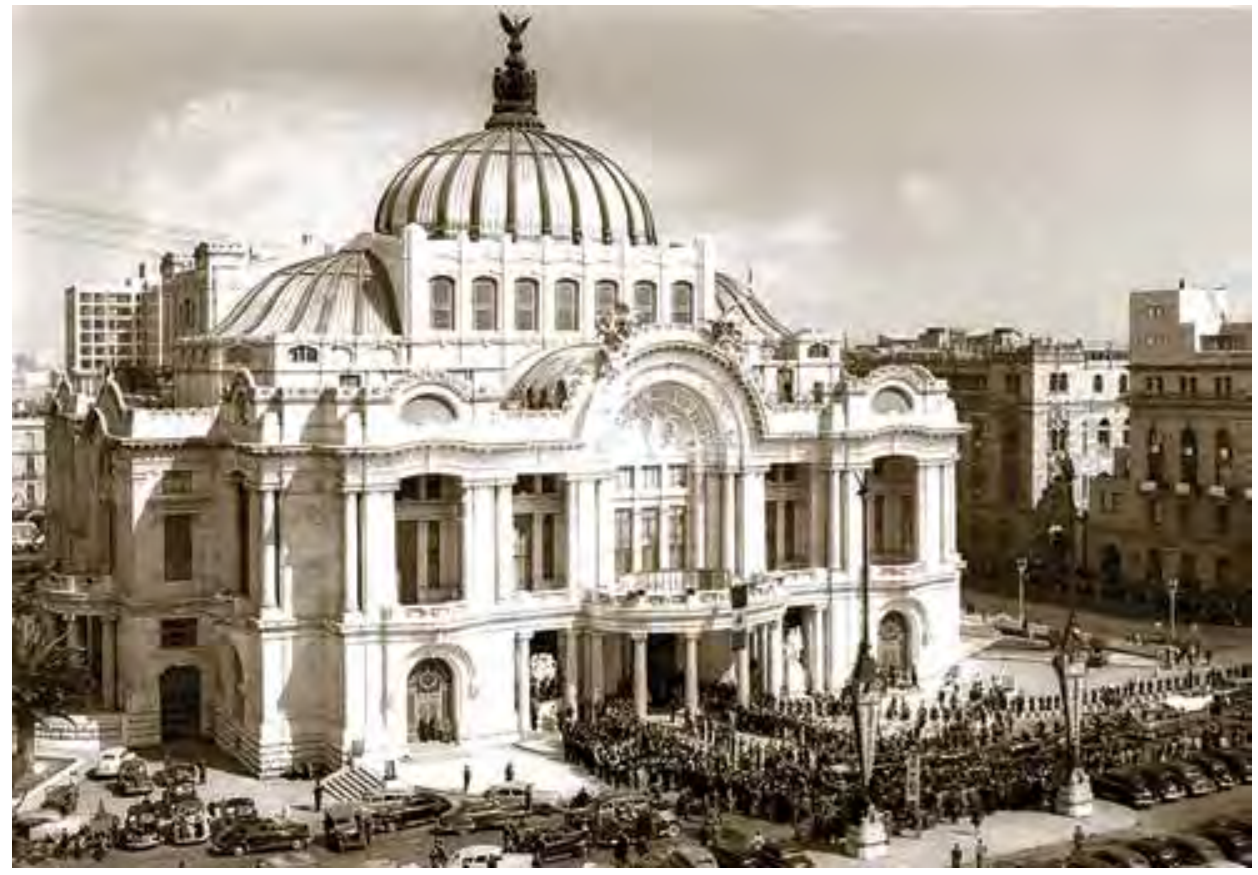

El desarrollo del eclecticismo arquitectónico en México es una etapa fundamental en la historia de la disciplina en el país. Basta revisar la selección de imágenes presentadas en la exhibición "Una Ciudad Imaginaria: Arquitectura Mexicana de los Siglos XIX y XX en Fotografías de Luis Márquez Romay”, realizada por la Universidad Nacional Autónoma de México, para comprender la influencia de aproximadamente 50 años que este tipo de diseño tuvo en el país.

El eclecticismo de las últimas décadas del siglo XIX influyó en el diseño de las construcciones eclesiásticas. Aunque las tendencias imperantes en la capital y el centro del país se basaron en diversas categorías estilísticas (neoclásicos, orientalistas, et. al.), las iglesias del Occidente de México adoptaron el neogótico como emblema. Este estilo fue una constante dentro de la arquitectura eclesiástica a partir del último cuarto del siglo XIX y las primeras décadas del siglo XX. El neogótico, como un nuevo lenguaje, más allá de lo arquitectónico, promocionaba una última y renovada defensa de la Iglesia y sus valores. Ello se sustentaba en la contraposición de la ideología católica con los gobiernos que se desarrollaron, primero, bajo ideologías liberales y, posteriormente, bajo la idea laica de progreso, sustentada por las nuevas dinámicas económicas (Checa, 20I2). La Iglesia requería de una visibilidad excepcional y encontró en el neogótico la manera de expresarla.

Las diócesis del Occidente de México concentraban en aquellos momentos la mayor cantidad de creyentes y fieles adheridos a las doctrinas conservadoras radicales promovidas por la jerarquía católica: "esa jerarquía eclesiástica proponía la restauración del papel de la Iglesia retomando el esplendor de ésta en época tardo medieval, de ahí que se promoviese el uso de estilos gotizantes para la construcción o la refracción de templos" (Checa, 
20I2, p.3). La convergencia de estos factores determina una zona de desarrollo específica y fructífera para el estilo neogótico en los estados del occidente del país: Michoacán (Templo de Zamora), Colima (Templo de Colima), Guanajuato (Templo de León), Nayarit, Durango, Aguascalientes y Jalisco (Templo de Arandas) (Checa, 2009). Es este el contexto en el que se inscribe la construcción del Templo Expiatorio del Sagrado Corazón de Jesús, en la ciudad de Guadalajara.

La influencia eclesiástica de Guadalajara es inseparable de su crecimiento y desarrollo urbano e icónico-arquitectónico. A partir de su última fundación el 14 de febrero de 1542, los barrios de la ciudad comenzaron a crecer con gran rapidez, superando en importancia a Compostela y resultando en el traslado de la Audiencia y del Obispado a la ciudad mediante la Real Cédula, dictada por Felipe II el 10 de mayo de I560. En aquel momento "la ciudad contaba con 2,500 habitantes" (AA.W., 1974, p.16). Posteriormente, se produciría un arribo continuo de diferentes órdenes religiosas (agustinos, dominicos, carmelitas, jesuitas, mercedarios); las mismas que edificaron iglesias y conventos en y alrededor de la ciudad. "Al levantarse el padrón de 1378, los cuarteles o lienzos de la ciudad eran 'cuatrocientos catorce' sin los que ocupaban los monasterios y templos, las casas eran I,54 I y los habitantes 8,0 8" (AA.W., 1974, p. 19). El obispo Juan Antonio Alcalde definió el crecimiento de la ciudad hacia el Norte al establecer la construcción de "dieciséis manzanas cerca de la Parroquia del Santuario, para gente humilde" y en 1784 los feligreses sumaban 22, I63. Durante el siglo XIX, Guadalajara continuó con su crecimiento hacia el Norte, Noroeste y Este, y en años posteriores a 1850, la ciudad contó con cerca de ochenta mil habitantes (AA.W., 1974, p.27). Durante las últimas décadas del siglo XIX y, como consecuencia de las Leyes de Reforma, edificios antiguos adquirieron diversos usos seculares, se introdujeron los tranvías y, finalmente, la luz eléctrica en 1884 .

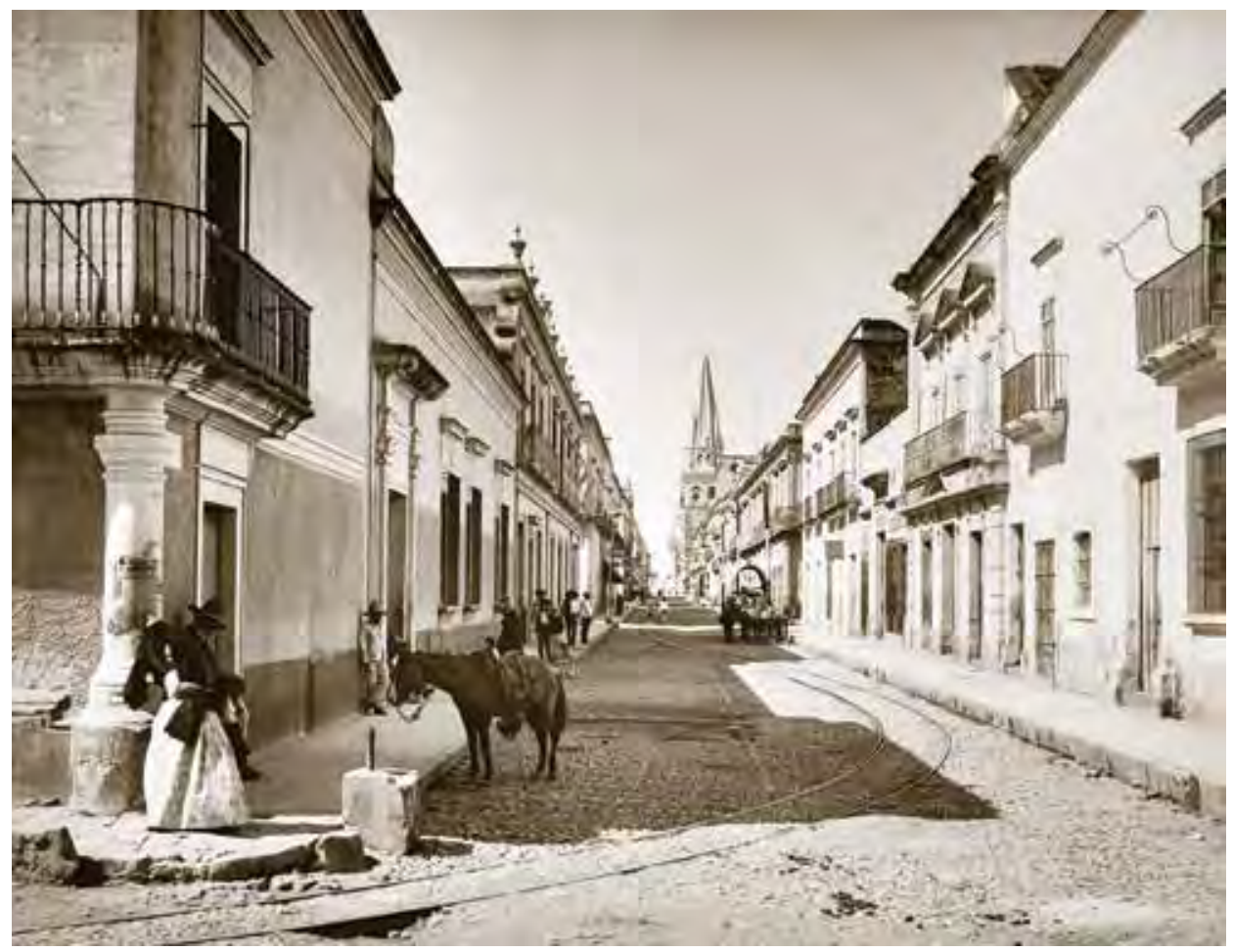

Aunque la separación de la Iglesia y el Estado y la revocación de los bienes de la primera, durante el periodo juarista ( I858- I872), mermó el poder de la jerarquía católica, la impor-
Figura 4. Vista de la calle 16 de Septiembre, oriente-poniente. Al fondo se observan las torres de la Catedral de Guadalajara. Fuente: Jackson, William Henry. Recuperado de $h$ ttps://revisionesgdl.com/2013/05/03/ guadalajara-en-imagenes-|880-/897| 
Figura 5. Adamo Boari, responsable del diseño del Palacio de Bellas Artes en la Ciudad de México y el Templo Expiatorio del Sagrado Corazón en Guadalajara.

Fuente: Recuperado de https://

grandescasasdemexico.blogspot.mx/2014/09/

la-casa-boari-dandini-en-la-colonia-roma.htm

tancia de la diócesis de Guadalajara y su hegemonía dentro de la región Occidente continuó ejerciendo una influencia definitiva en el contexto cultural de la zona ${ }^{3}$.

Es dentro de este contexto cuando comienza la gestación y construcción del Templo Expiatorio del Santísimo Sacramento. En un ensayo titulado "Breve Relación sobre el Templo Expiatorio", se menciona que un grupo de tapatíos -entre los que estaría el abuelo de Ignacio Díaz Morales, arquitecto del Templo Expiatorio de 1927 a 1972-, crearon una comisión encargada de construir un Templo Expiatorio del Santísimo Sacramento. No queda claro si la comisión tuvo la iniciativa o se siguieron las indicaciones dadas por el Prelado Metropolitano, Pedro Loza y Pardavé, buscando proyectos para la ejecución del citado templo. Concebido como una obra que permite recuperar la preeminencia del catolicismo dentro de la sociedad tapatía, el templo para la expiación -reparar, de una manera perfecta, los pecados, por medio de algún sacrificio, sufriendo la pena estipulada por un tribunal divinoes definido por Checa como una construcción:

Monumental desde su inicio, con el único propósito de ser un expositor del cuerpo de Cristo, 24 horas al día durante los 365 días del año, capaz de promover el perdón y la expiación por los ataques a la Iglesia Católica por parte del Estado, que han permitido la libertad de cultos y han dado como resultado la presencia en Guadalajara de grupos protestantes. (Checa, 2009, p.24)

La elección del proyecto se realizó mediante un concurso en el que fue seleccionado el diseño del arquitecto Adamo Boari. La primera piedra fue colocada el I 5 de agosto de 1897.

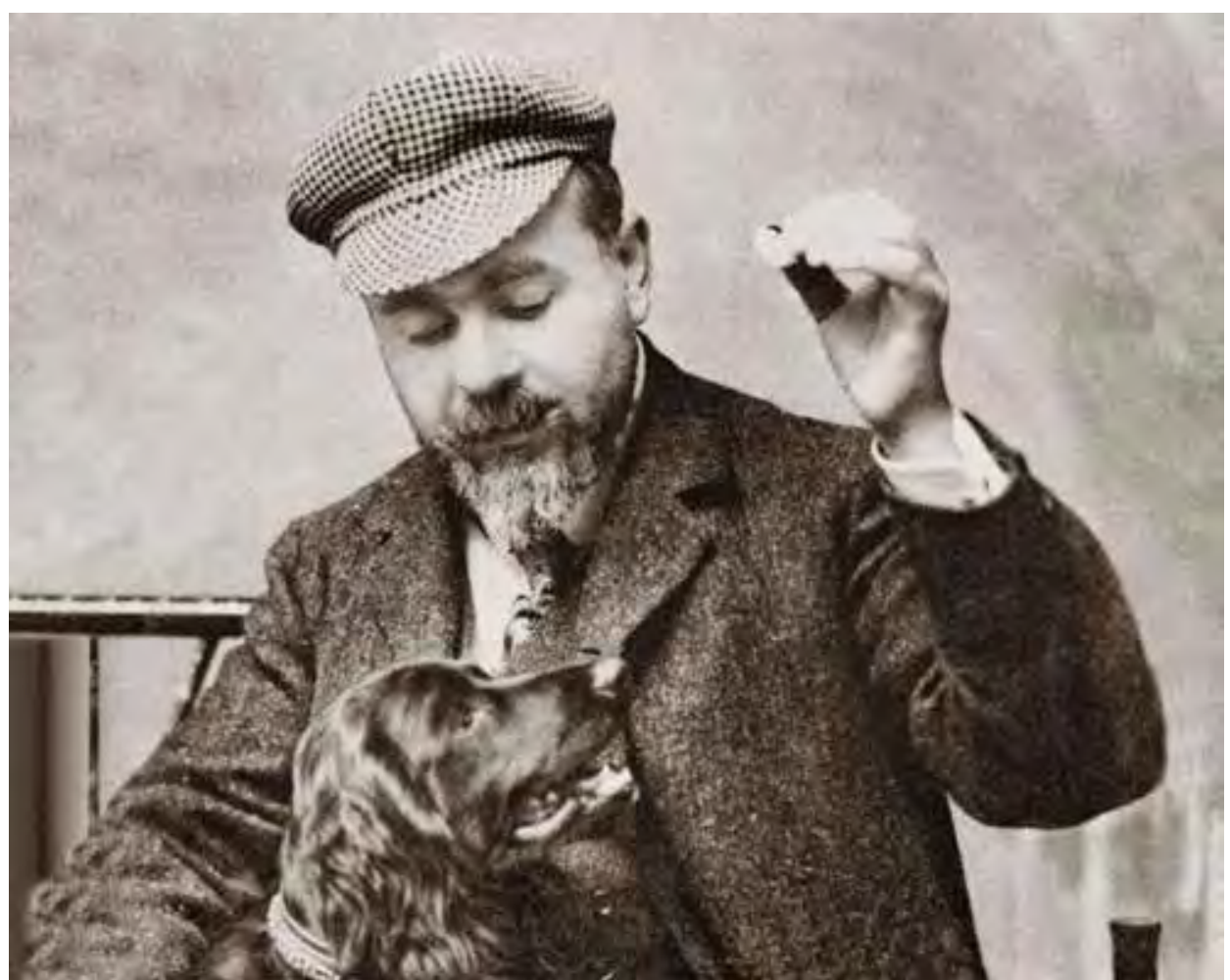

3 "La Arquidiócesis de Guadalajara mantiene rasgos de preeminencia nacional que se expresa en que: I) 'el Arzobispado de Guadalajara fue el primero en la historia de México en contar con un cardenal: José Garibi Ribera'; 2) desde la época colonial hasta nuestros días, Guadalajara ha sido un importante centro de vocaciones sacerdotales; 3) el Seminario de Guadalajara es el más grande de América Latina (Alba y Kruijt, 1988: 234-235), y; 4) Guadalajara es el segundo centro de instrucción para religiosos en el mundo sólo después de Roma". (De la Torre, 2006, p. 106). 
Adamo Boari fue el encargado de ejecutar la construcción del Templo Expiatorio, entre I897 y 190I. Durante esos años, Boari se encontraba en la Ciudad de México para participar en los otros proyectos encargados por el General Porfirio Díaz. Sin embargo, no tuvo oportunidad de terminar el proyecto. La Revolución Mexicana fue la causa de detención de las obras, ante la falta de recursos monetarios y humanos. El Templo Expiatorio sufrió la misma situación de incertidumbre que en aquel momento se extendía por todo el país. Esta etapa definió un punto de inflexión para el desarrollo arquitectónico del Templo Expiatorio. Después de abandonar Adamo Boari la obra y, a pesar de contar con un proyecto y planos elaborados, el encargado de su continuación fue el canónigo Pedro Romero, quien decidió no solicitar ayuda profesional alguna argumentando que él era suficientemente competente para llevar a cabo la ejecución junto con un maestro de obras de nombre Feliciano Arias. Romero diría que: "Pues entre el maestro de obras y yo, porque ya teniendo los planos ipara qué necesitamos ingeniero?" (Mata, 1979, p.3 I2). El proceso, como podría suponerse, fue accidentado y presentó una serie de errores, sobre todo constructivos, derivados de obviar los aspectos estructurales de la obra. ${ }^{4} \mathrm{Hacia}$ I $91 \mathrm{I}$ ya estaban terminadas las columnas y muros interiores hasta la altura de los capiteles como se puede observar en la Figura 6, pero el proceso de la construcción fue constantemente interrumpido por la lucha armada, después por la persecución religiosa y por la crisis económica resultante de estos eventos.

Las obras se suspendieron entre los años 1912 y 1919. Retomarlas significó, también, modificar la expresión original del templo y someterlo a un proceso histórico continuo de revisión y adaptación, el cual finalizó con un proyecto distinto en la década de 1970, como lo muestra la Figura 7.

En 1927 y por orden del arzobispo Francisco Orozco y Jiménez, el canónigo José Garibi Rivera (quien posteriormente se convertiría en primer cardenal de la Arquidiócesis de Guadalajara) se hizo cargo de la edificación. Habiéndose perdido los planos originales de Adamo Boari, Garibi Rivera solicitó la ayuda del ingeniero Luis Ugarte quien participó en la construcción del coro. Posteriormente, el ingeniero Pedro Castellanos fue considerado para continuar con la obra. Sin embargo, a pesar de la empatía que Garibi Rivera sentía hacia Pedro Castellanos, resultado de su conversión en sacerdote de la diócesis, el regionalismo que desarrollaba en ese momento en sus obras arquitectónicas, lo condujo a ser desestimado para proseguir con la construcción. Lo que separó por completo a Pedro Castellanos de la obra del Expiatorio fue su propuesta sobre re-planificar la construcción del templo en un estilo gótico flamígero, muy diferente al de los planos originales planteados por Adamo Boari. Así, la obra recayó en Ignacio Díaz Morales. El encargo que recibió por parte de la jerarquía católica de la ciudad constituyó el proyecto de mayor duración y trayectoria en la vida del arquitecto, un proyecto que se prolongaría por 45 años.

Ignacio Díaz Morales, uno de los arquitectos más importantes de la historia de Guadalajara, y el más polémico con su proyecto de la Cruz de Plazas $^{5}$, es la figura que permite comprender la función del Templo Expiatorio como puente: fue el representante que enlazó el estandarte ideológico del eclecticismo arquitectónico eclesiástico con una nueva etapa en la arquitectura tapatía que "pasaba de una posición tradicional a una tendencia a lo moderno” (Kasis, 2004, p. 109). Ignacio Díaz Morales retomó los conceptos estilísticos del

$4 \quad$ Las deficiencias constructivas consistían en columnas construidas de rajuela de cantera recubierta de un listón de $15 \mathrm{~cm}$. de espesor de piedra roja de Santa María y que mostraban una deficiencia en cuestión de resistencia. A esto se sumaba la cimentación a $1.50 \mathrm{~m}$ de profundidad que no permitía la transmisión de cargas de manera homogénea.

5 La Cruz de Plazas fue un proyecto en la ciudad que implicó la demolición de manzanas enteras para consolidar una forma de cruz, en planta, a partir de plazas, donde la manzana central la ocupaba la catedral de Guadalajara. "Desde la azotea (de Catedral) contemplé las dos manzanas que estaban detrás, las cuales estaban rodeadas por una serie de edificios de gran valor arquitectónico, y se me ocurrió pensar en una gran plaza: desde la misma azotea miré al Norte y al Poniente, y vi un jardín y un espacio sin objetivo. Fue entonces cuando concebí la idea de proyectar una Cruz de Plazas” (Kasis, 2004, p. 109). 
Figura 6. Obras del Templo Expiatorio, fachada oriente, alrededor de 1927. Se distinguen los cuerpos de base y los pilares.

Fuente: Recuperado de http://

guadalajaraayeryhoy.blogspot.mx/2013/I0/ templo-expiatorio-1927.html

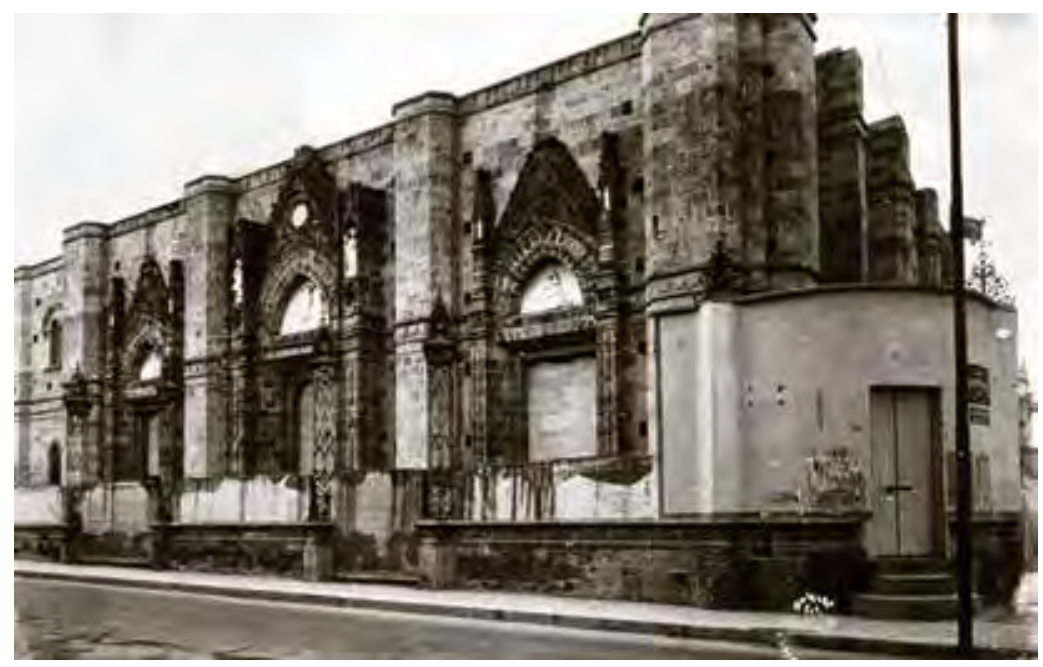

Figura 7. Templo Expiatorio, fachada oriente, alrededor de 1970

Fuente: Recuperado de: $h t t p: / /$

guadalajaradeayer.blogspot.mx/2009_05_0I_ archive.html

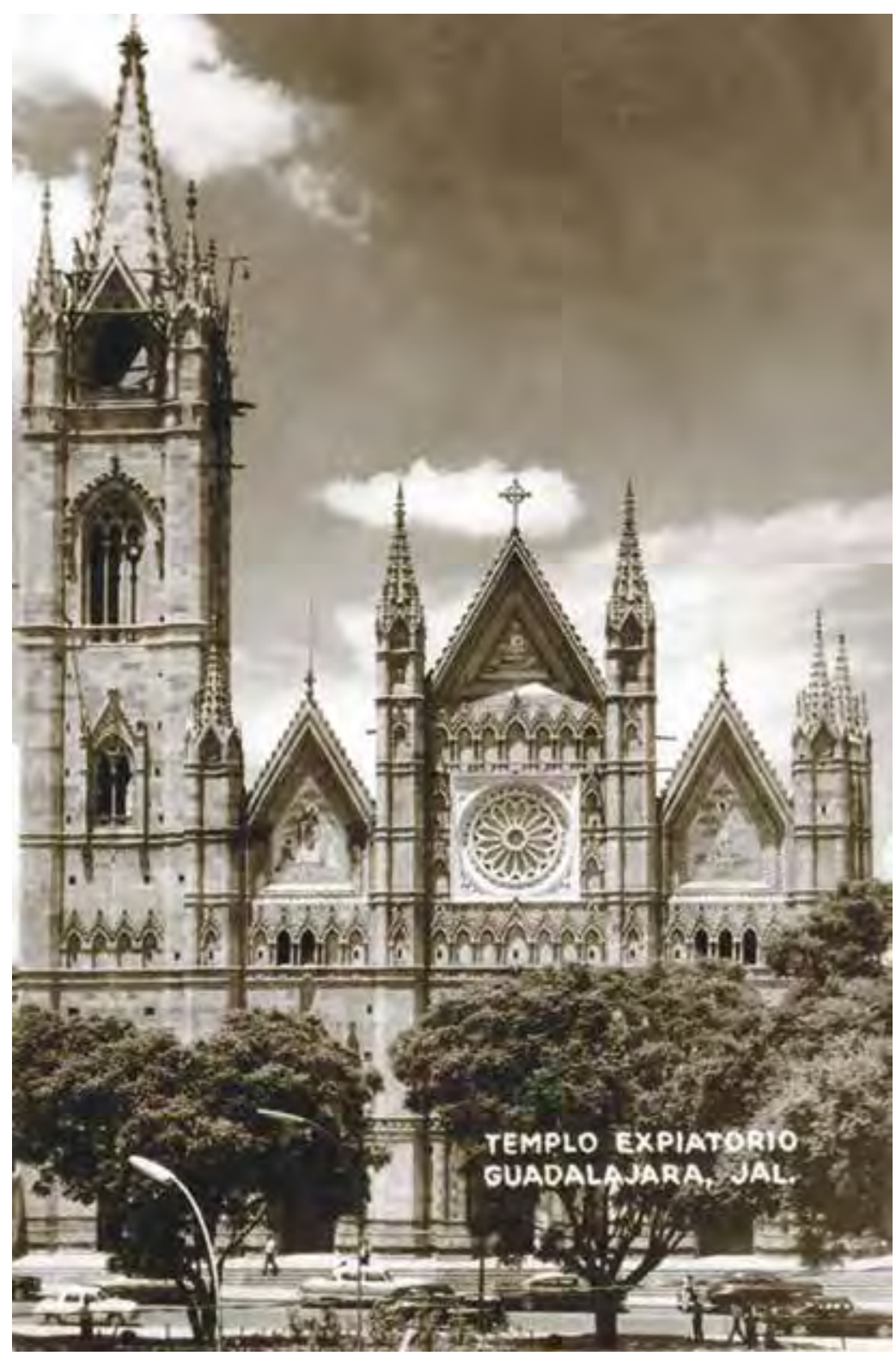


gótico e introdujo diversas adecuaciones y modificaciones al proyecto original de Adamo Boari. Estas adaptaciones, incluyeron la anexión de un volumen distinto al proyectado por Boari y cuyo objetivo era el de contener "la sacristía, las dependencias de la adoración nocturna, la casa del capellán, el claustro, un salón de conferencias, el palacio episcopal y servicios" (Kasis, 2004, p. 108).

Díaz Morales tenía claro que se debía mostrar cuál era el nuevo cuerpo y los métodos constructivos de la época utilizados para crearlo, dando a conocer la intervención de acuerdo con los nuevos requerimientos programáticos, distintos a los del uso original. De esta manera, el arquitecto mostraría los diferentes conceptos estructurales usados en esa parte específica del edificio, una losa de concreto aligerada en forma de casetones que tras retirar la cimbra generó un vacío reticular que va en direcciones opuestas, resolvió los grandes claros y al mismo tiempo, con tecnología actual (creada desde 1960), logró una integración formal con la utilizada en el edificio original, aunque contrastando con la ejecución del interior del templo a base de piedra cortada. Las modificaciones realizadas en los interiores condicionadas por los problemas existentes debido al trabajo dirigido por el canónigo Pedro Romero. Las columnas fueron sustituidas y el estilo del interior cambió a un gótico francés como se puede apreciar en la Figura 9.

No obstante, en un inicio la participación de lgnacio Díaz Morales en este proyecto religioso fue cuestionada por él mismo, debido a su apego hacia las nuevas propuestas de la arquitectura moderna que lo impulsaban a rechazar la construcción de algo que se podía considerar como un retroceso, algo fuera de época 6 .

Aunque existió una reticencia primaria por parte de Díaz Morales para participar en el proyecto, dada la construcción prexistente, la afinidad con la teología, la escolástica y un idealismo platónico subyacente, permitieron la proximidad y aceptación de un encargo eclesiástico que encarnaba los valores que Díaz Morales apreciaba ${ }^{7}$.

Son estas condiciones las que también crean un enlace entre las ideas de la jerarquía católica del Occidente de México y la ejecución de una obra más cercana a la exploración mística, en contraste a las propuestas y teorías modernistas. Díaz Morales se convierte en una síntesis entre diversas tradiciones que permiten avanzar con un eclecticismo cuyo momento había ya pasado.

Si bien la arquitectura desarrollada en la Guadalajara de esa época comenzaba a manifestar una tendencia hacia la modernización y la contemporaneidad contenidas en los supuestos del Estilo Internacional, el Templo Expiatorio constituye un símbolo que refleja las preocupaciones de un autor por concluir una obra cercana a su ideología. Este templo representa la capacidad de Díaz Morales para traer:

A la arquitectura referencias de otros medios, en un sentido totalmente acorde al pensamiento enciclopedista de otra época y al modo en que antiguamente se trabajaron los tratados de arquitectura, otra rica fuente para él; atendió con gran cuidado los escritos de Vitrubio, Alberti y Palladio. El destino de las

6 "Naturalmente, yo me defendía para no aceptar semejarte carga, porque profesionalmente he creído que no debíamos hacer Gótico; mas el señor Garibi me dijo, más o menos: 'Pero, mire usted, no es que vayamos a hacer un edificio gótico, sino que los padres antiguos nos han dejado un edificio tan adelantado en gótico, que no podemos destruirlo, por lo que no tenemos más remedio que terminarlo en gótico'”. (Kasis, 2004, p. 49)

7 En la monografía de Díaz Morales, Kasis (2004) especifica: "Díaz Morales consideraría también como elemento fundamental la lectura y el análisis de textos como Arte y escolástica, de Jacques Maritain, y la obra de los neotomistas, sin dejar de recurrir a la fuente original, Santo Tomás y Platón. La escolástica y la mayéutica, representarían focos de atención especial” (p. 49). 
Figura 8. Interior del claustro del Templo Expiatorio, adición de Ignacio Díaz Morales al proyecto original de Adamo Boari. En la esquina superior derecha se observa la utilización de casetones y concreto armado para la losa de cubierta.

Fuente: José Manuel Falcón Meraz, 2015

Figura 9. Interior del Templo Expiatorio detalle Crucero.

Fuente: José Manuel Falcón Meraz, 2015.
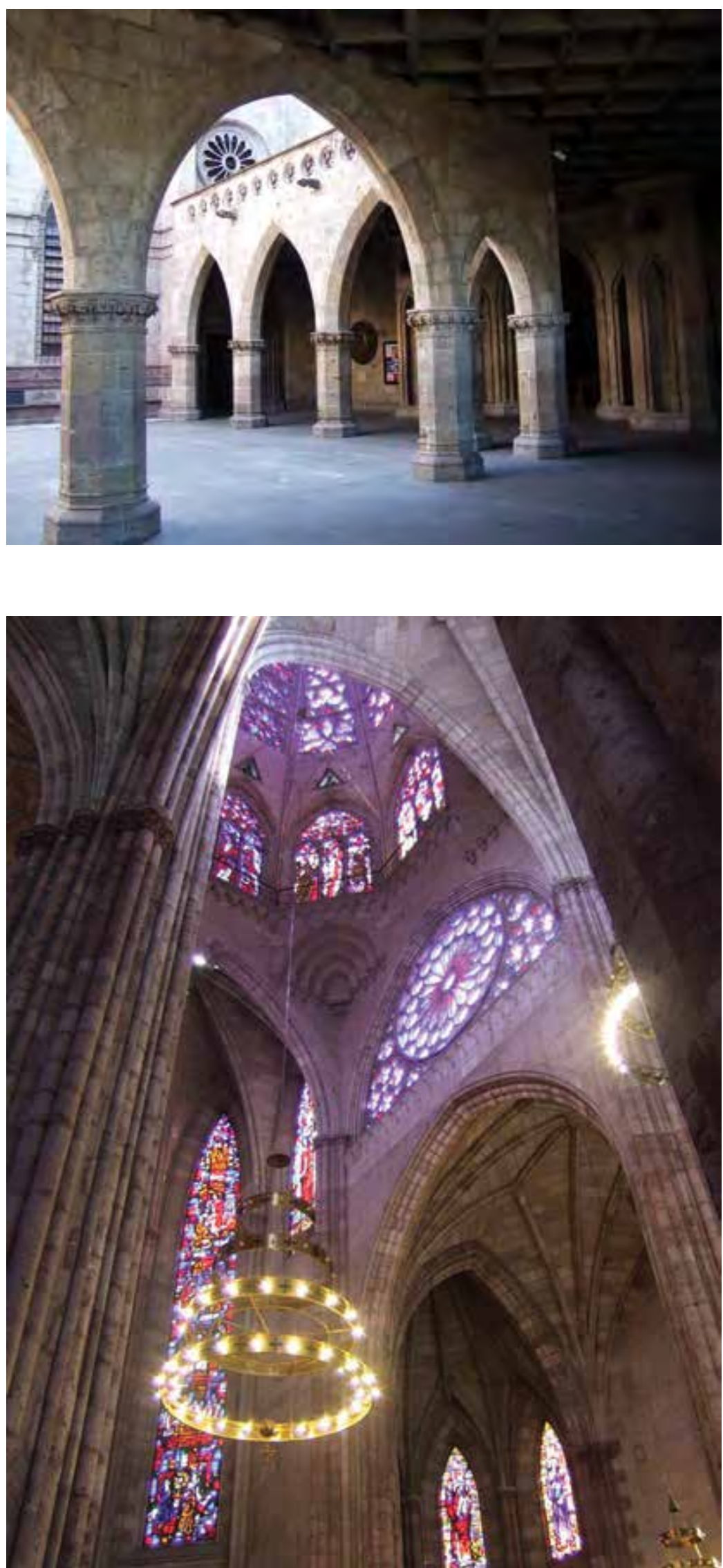


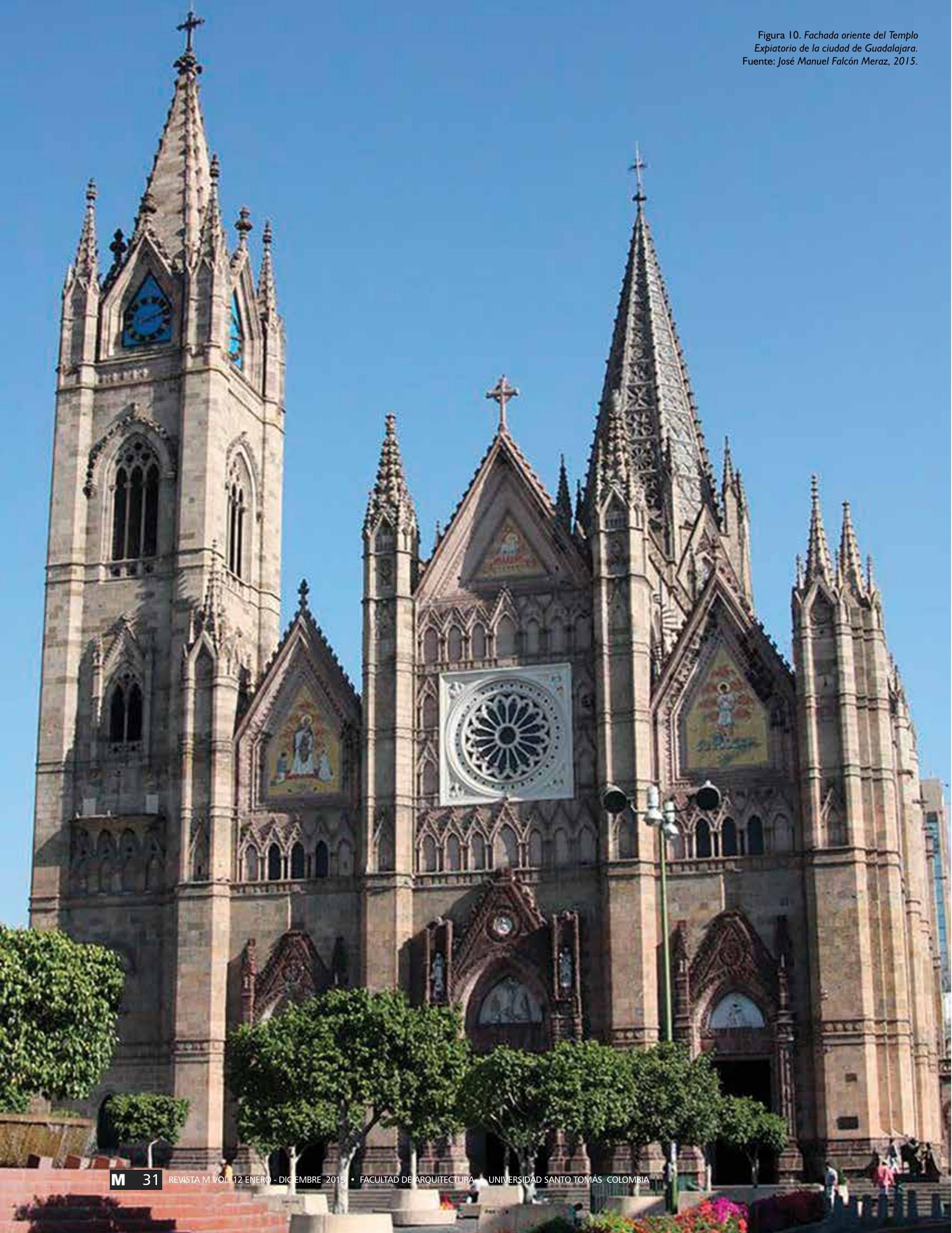


ideas y los contenidos fue siempre una teoría de la arquitectura que era por él construida y procesada, así como su aplicación al campo de la docencia y de la práctica de la arquitectura, áreas en que se hacen presentes los tres valores trascendentales: verdad, bondad y belleza en equilibrio. (Sordo, 1985, p. 8)

El Templo Expiatorio es una síntesis de estas condiciones de pensamiento. Más allá del problema histórico que significaba el desarrollo de un neogótico en una ciudad que miraba hacia nuevos horizontes arquitectónicos, la obra es una muestra de lo que para Díaz Morales contenía en sí la práctica de su profesión: "La revelación de la armonía en medio de una comunidad. Conciencia de origen y destino; humano, no hedonista. La consecución del acto perfecto" (Kasis, 2004, p.49).

El desarrollo del Templo Expiatorio como catalizador de una vivencia espiritual de la práctica arquitectónica constituyó también un proceso de aprendizaje. Las ideas que volcó Díaz Morales en la obra, ejercieron su influencia en personajes que definieron la arquitectura tapatía de la segunda mitad del siglo XX. Uno de ellos, el ingeniero Miguel Aldana Mijares, relata cómo fue contratado por Díaz Morales para elaborar los dibujos sobre los cortes de piedra que debían elaborarse en la construcción del templo. La negativa inicial de Miguel Aldana fue, sobre todo, un punto de partida para que Díaz Morales expresara, sumamente emocionado, cómo la posibilidad de construir una catedral no se presenta con frecuencia. Porque así ve Díaz Morales al Templo Expiatorio, como una catedral. El punto de reunión entre la tierra y el cielo, a la más completa usanza gótica. El entusiasmo de Díaz Morales va en aumento, en tanto describe con su elocuencia las relaciones entre la arquitectura, la construcción y el sentido de la vida. (Hernández, 2004, p.47)

Finalmente, Miguel Aldana aceptó el trabajo y comenzó un estudio profundo sobre los procesos constructivos necesarios para llevar a cabo la correcta realización de la obra. Para el ingeniero Aldana este trabajo fue fundamental como base para la comprensión del trabajo de constructor, de la eficiencia en los procesos de ejecución y el costo de obra resultó en un trabajo que declaraba hacer por placer: "No lo hacía por el pago, ya que éste me parecía insignificante. [...] De hecho, hubiera yo pagado por hacer ese trabajo. Lo que me importaba era el conocimiento que estaba adquiriendo con todo eso" (Hernández, 2004, p.50).

Durante 45 años el Templo Expiatorio adquirió su forma y constitución actual. En un extracto de la descripción que hace Díaz Morales sobre el Templo Expiatorio se menciona que la fachada principal se encuentra orientada al sur y está compuesta por tres naves, siendo la central de mayor elevación. Se busca con ello la verticalidad que sugiere la "cercanía al cielo" como se observa en la Figura II.

El ingreso se encuentra marcado por tres puertas hechas de madera de granadillo trabajadas por el maestro Jesús Gómez Velasco, con elementos de bronce realizados por Benito Castañeda y diseñados por el cardenal Garibi Rivera. En el frente del Templo hay tres tímpanos que incluyen el mismo número de mosaicos. Fueron elaborados en el Vaticano por el pintor Francisco Bencivenga, y en la nave central representan, al cordero Pascual, la oriental a San Tarsicio y la occidental a San Pío X. En el interior, las bóvedas son de tracería y las laterales de tercelete? ${ }^{9}$ Se explica que las bóvedas de la nave central son

8 En una entrevista, Díaz Morales criticaría a sus contemporáneos, declarando que: "Los arquitectos estaban más preocupados por [...] copiar viejos estilos de Europa que por buscar algo acorde con la época y el lugar" (Sordo, 1985, p.8).

9 Estas bóvedas están recargadas sobre cuatro puntos y el tercelete es cada uno de los nervios que van desde los puntos de apoyo y se unen con los otros nervios secundarios que descienden desde el centro de la bóveda. 

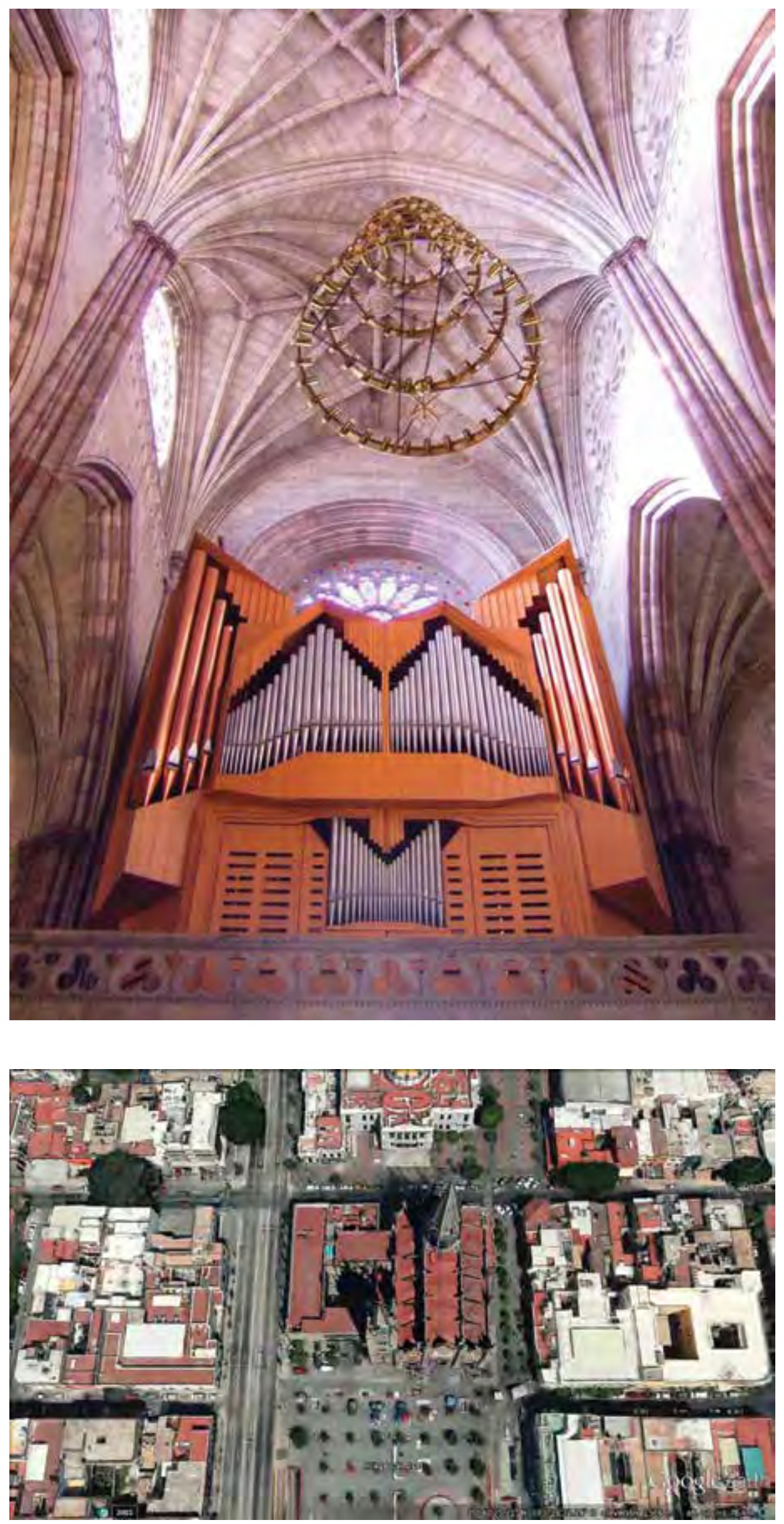

Figura II. Interior del Templo Expiatorio: órgano y detalles de arcos y bóvedas.

Fuente: José Manuel Falcón Meraz, 2015.
Figura 12. Fotografía aérea donde se observa la volumetría del Templo y la conexión de la nave Oriente con el claustro.

Fuente: Tomado de Google Earth, 2015 
compuestas y sus ventanales son rosetones de traza circular.

La nave lateral del lado Oriente se comunica con el claustro dispuesto en forma de "L" y se conecta con el baptisterio, la cripta grande y la escalera hacia la logia. Por la logia se tiene acceso a un gran ventanal que se proyecta hacia el claustro y hacia la plaza y que cuenta con una terraza que es la azotea del brazo Oriente del claustro (Figura 12). El claustro se encuentra techado por casetones de concreto armado, comunica a la capilla del Santísimo y termina en la calle de López Cotilla. Está descrito que en la cripta principal -la más grande- se dispuso una serie de columbarios que fueron colocados debajo de ventanas que dan a la calle Enrique Díaz de León. Al fondo, existe una escultura de la Piedad sobre un mosaico masivo de origen italiano; dicha escultura está hecha de mármol blanco y es obra de Don Adolfo Ponzanelli. Se sabe que el reloj fue regalo de Pablo Horn, quien presentó la iniciativa a los "Sembradores de Amistad", un grupo religioso de trascendencia local, quienes estuvieron de acuerdo. El reloj fue adquirido en Alemania, en la casa Korfhage de Osnarbrück; éste tiene cuatro manecillas que se iluminan automáticamente al caer la noche por medio de una celda fotoeléctrica.

En 1972 Díaz Morales concluye su participación en la obra del Templo Expiatorio, exonerado de esta tarea por el entonces séptimo arzobispo de Guadalajara, Dr. Don José Cardenal Salazar López. Este año también muere el cardenal Garibi Rivera. El arquitecto Díaz Morales se deslindó de cualquier responsabilidad en los cambios posteriores realizados en el templo estableciendo que:

Se han tomado licencias de ciertas determinaciones que no fueron proyectadas por mí, como algunas hojarascas, como la terminación de ciertas cornisas en tobogán, etc. Y, habiendo sido requerido en algunas ocasiones de que entregara los planos, tuve que decir que no existían [...]. (Mata, 1979, p. 312)

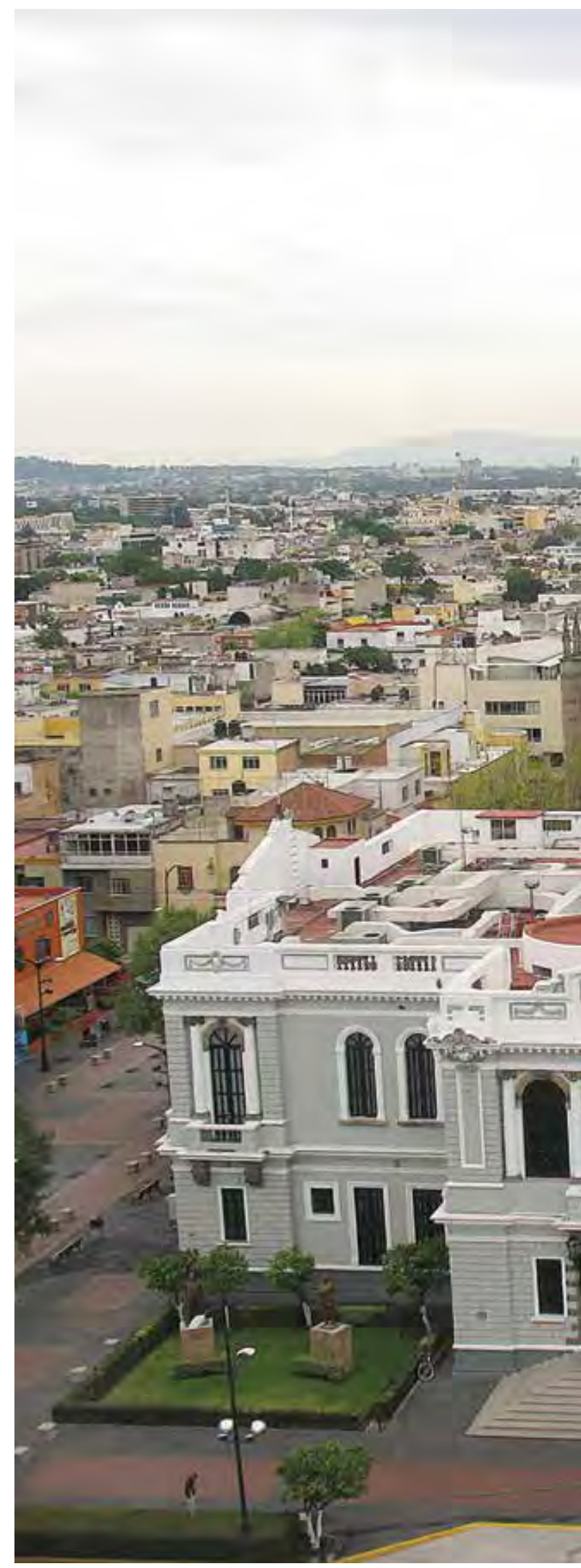


Figura 13: Fotografia aérea del contexto del

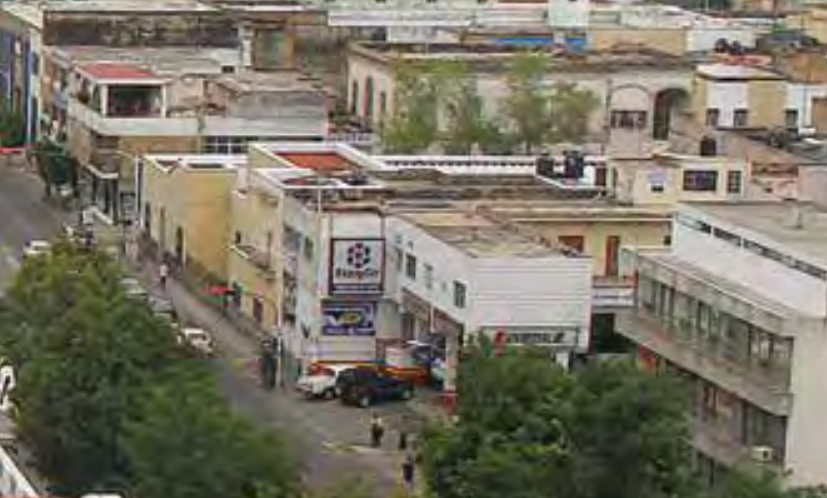

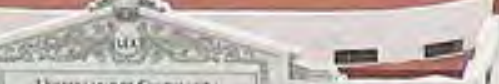

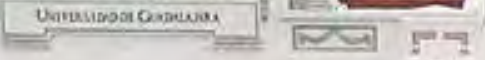
1
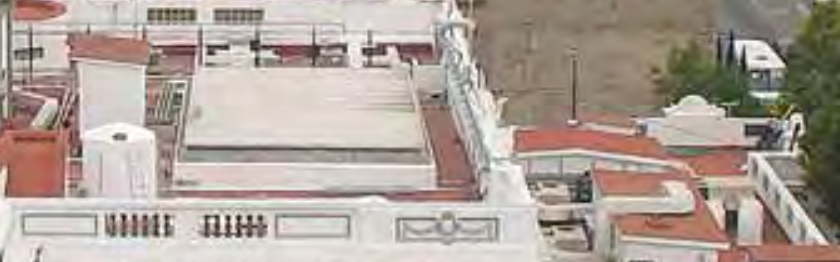

(1)

$$
\text { A }
$$

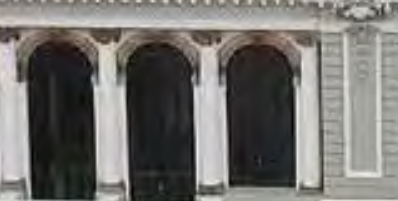

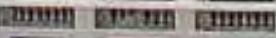
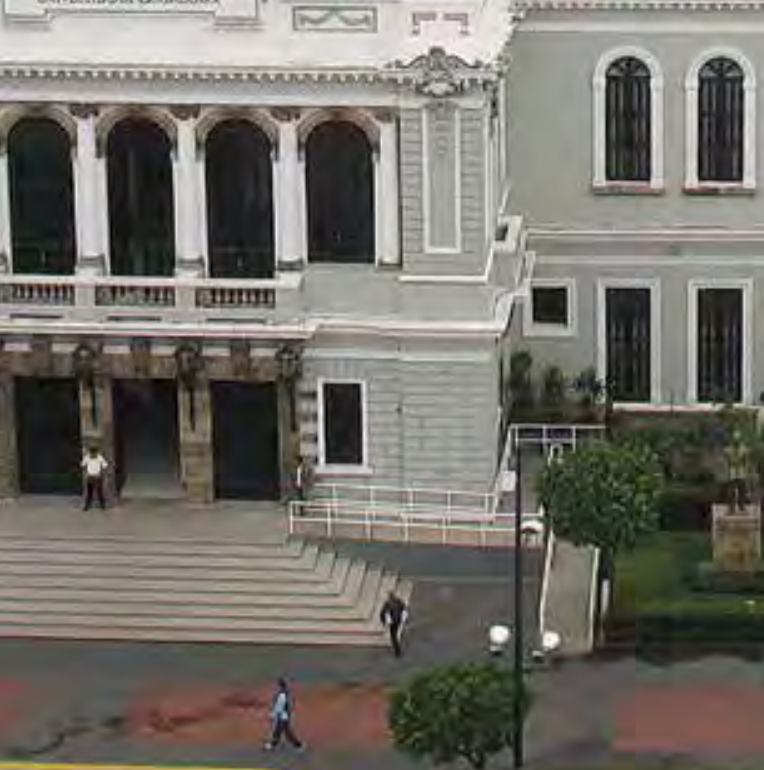

\section{4}
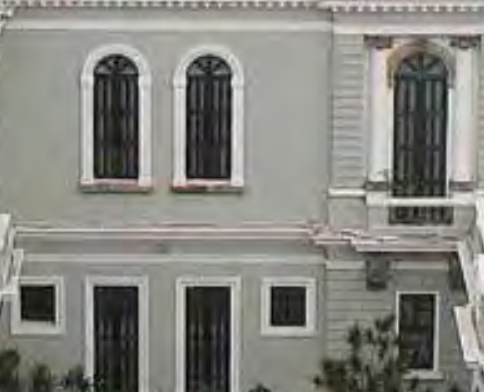
$\rightarrow$.
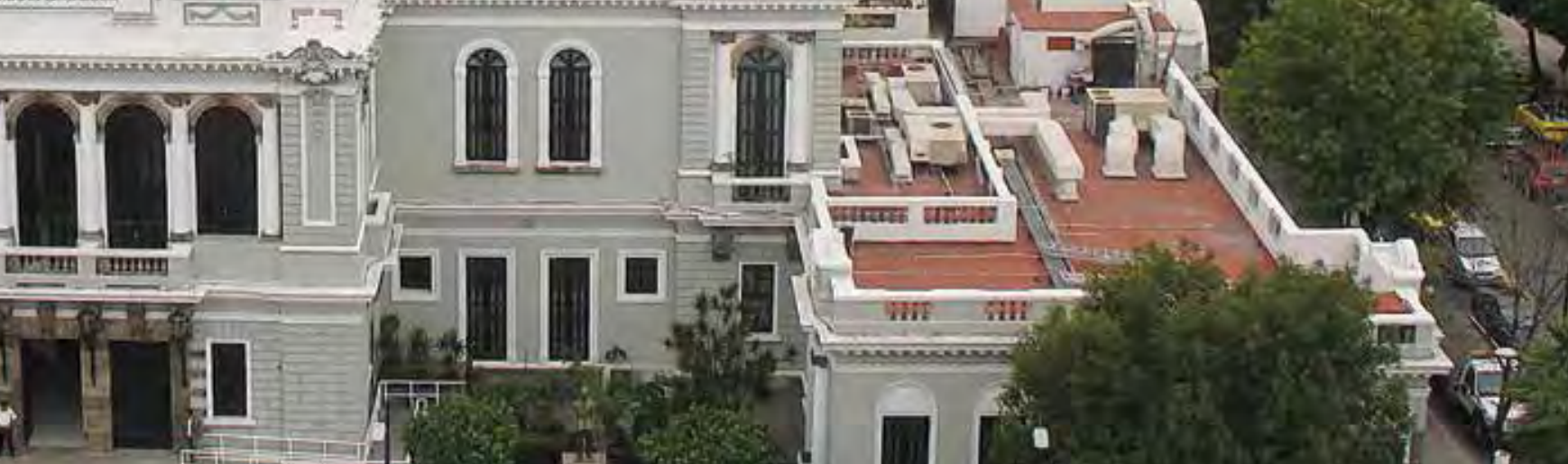

(7.
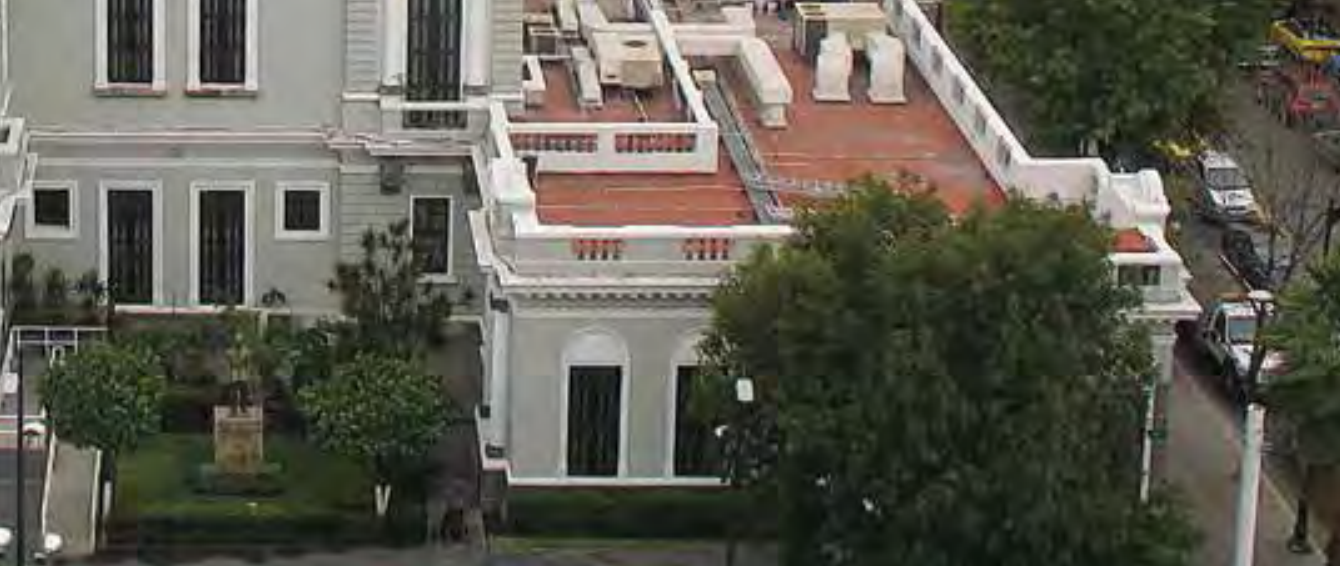

$\lambda$

v
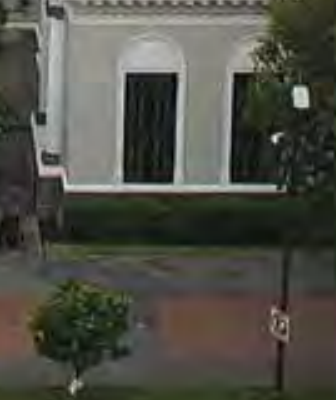

$-9$

12
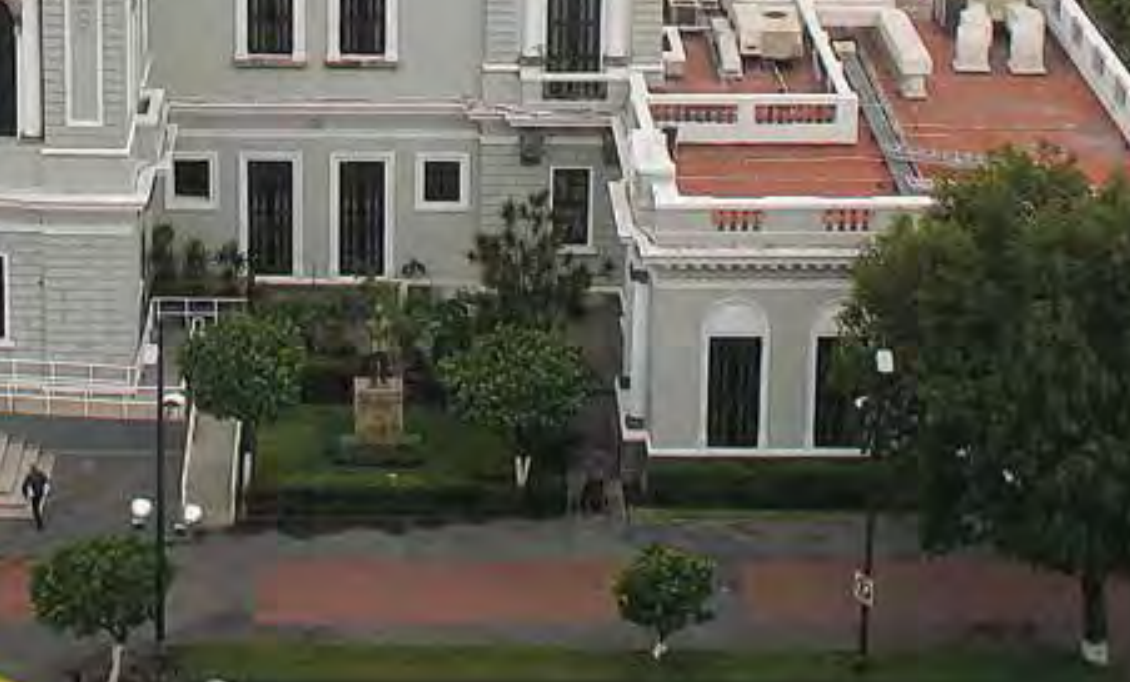
Figura I4. Función de lucha libre en la plaza pública del Templo Expiatorio.

Fuente: Fisher, Gwyn (20/4). Recuperado de: https://agaveweb.com/blog/el-temploexpiatorio-de-guadalajara/
Sin embargo, es posible establecer que para el momento en que Díaz Morales se retira de esta empresa, la construcción estaba prácticamente concluida. Después de esta fecha, se llevaron a cabo únicamente otras obras complementarias que consistieron en la finalización de acabados y ornamentos previamente iniciados.

El Templo Expiatorio sobrevive actualmente como símbolo en una ciudad preocupada por la pérdida de su identidad y que añora épocas pasadas. Los cambios experimentados por la ciudad han tenido como consecuencia la pérdida de su patrimonio arquitectónico, resultado de una "inadecuada cultura generalizada y predominante de ciudadanos y gobernantes" (Hernández, 200 I, p. 19), que han sido incapaces de llevar a cabo los procesos de modernización urbana integrando a ellos la existencia de construcciones características de la evolución de la ciudad. En este contexto, el Templo Expiatorio sobrevive como enlace entre diversos momentos históricos. Hoy, su localización se ha mantenido y consolidado como un centro neurálgico de la ciudad, con edificaciones vecinas generadoras de una actividad urbana importante, como el Paraninfo y la Rectoría de la Universidad de Guadalajara (Figura I 3).

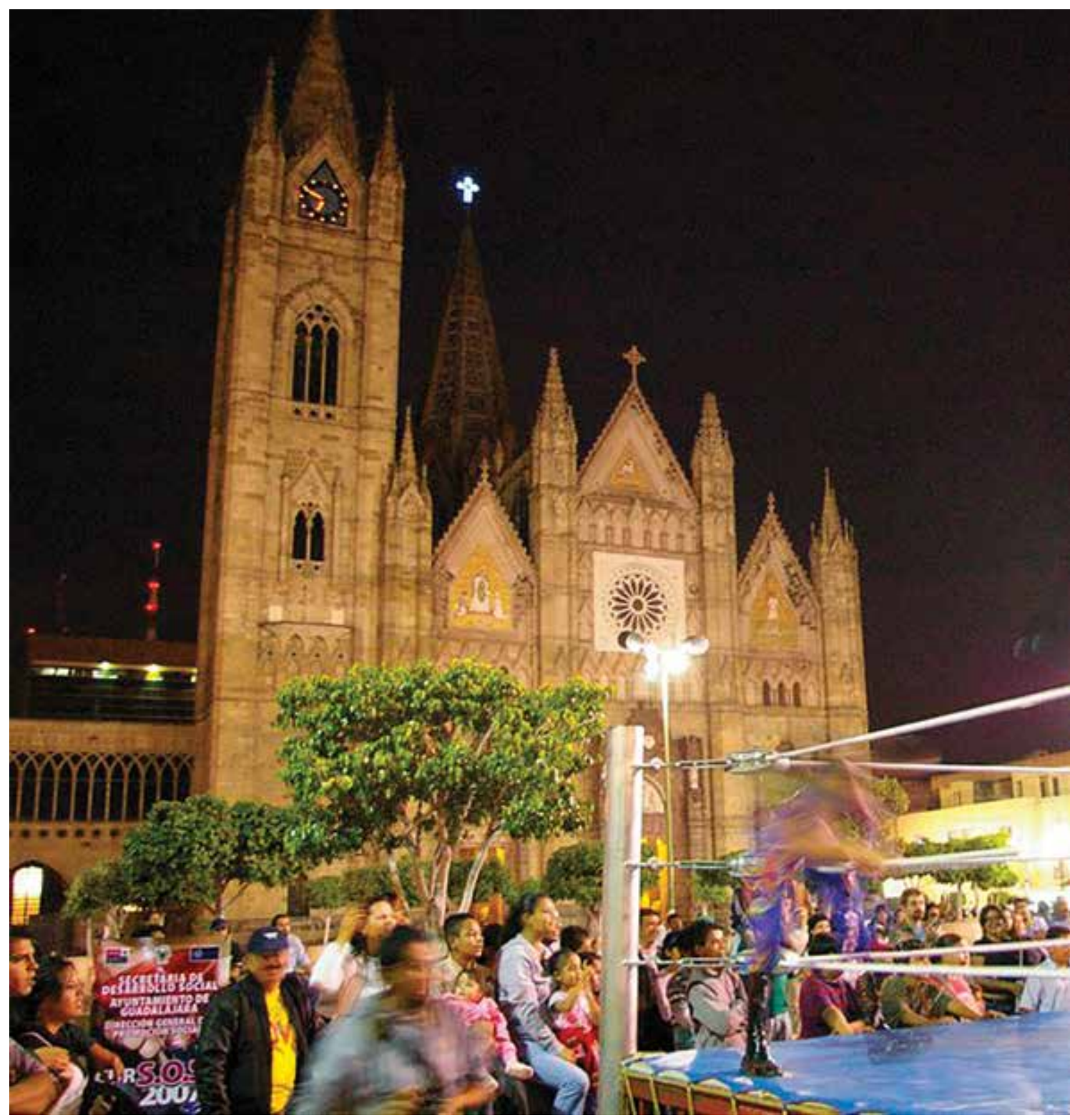


Así pues, el Templo Expiatorio, iniciado como un materializado testamento ideológico de la Iglesia Católica, es hoy un referente que actúa como hito urbano y que aglutina diversas actividades y expresiones de apropiación del espacio tanto interior como exterior.

Si bien el Templo Expiatorio se inscribió, en un inicio, dentro de una expresión particular sobre el significado de la Iglesia en ese momento específico, representa hoy un "papel que no es ya sólo religioso sino también cívico y social y que recientemente, ha introducido a esos templos [neogóticos] en el terreno del turismo y el marketing de ciudad" (Checa, 2012, p.2). Parte de la apropiación del Templo Expiatorio por los habitantes de Guadalajara se relaciona con su estética particular haciendo que sea identificado como un edificio único. A esto se suma la utilización del espacio para diferentes servicios religiosos conmemorativos y realización de conciertos. Aunado a ello, la plaza proyectada por Ignacio Díaz Morales en 1986, por encargo del Ayuntamiento de Guadalajara, y concluida en 1992, es el marco para el desarrollo de una activa vida urbana, que lo ha consolidado como un lugar de disfrute de la ciudad y de las experiencias urbanas. El testimonio de uno de los visitantes demuestra la constitución del templo y su plaza adyacente como un espacio público relevante en el que se manifiesta lo diverso:

El Expiatorio tiene todo lo que se le podría pedir a un centro urbano de reunión. Su arquitectura gótica es imponente [...] A su alrededor existen cafés, librerías y la plaza siempre está llena de ancianos y niños [...] Hay gente muy docta vendiendo libros y los domingos es posible ver a los mayores bailando danzón y comiendo elotes y churros mientras los niños corren y juegan entre las palomas (Víctor, 20 I5, foro en línea).

El Templo es ahora una glosa característica que la ciudadanía se ha apropiado, y que continúa irguiéndose como un puente entre distintas épocas y distintas expresiones (Figura 14).

\section{ARQUITECTURA DE REFERENCIA Y SÍNTESIS}

Más de un siglo después de haber sido decidida la construcción de un templo de estilo neogótico, el Expiatorio ha adquirido nuevos significados que se integran a los antiguos: se inserta en un período de construcción de obras eclesiásticas en el Occidente de México que hacen del neogótico un leitmotiv particular; es un reflejo de las influencia del eclecticismo en la arquitectura mexicana producida en las décadas que abarcó el 
gobierno del general Porfirio Díaz y funcionó como un catalizador de una generación de arquitectos que definió lo que posteriormente se llamó la "Escuela Tapatía de Arquitectura".

Esta edificación reúne las características de la recreación arquitectónica de estilos históricos que se extendieron en México desde las últimas décadas del siglo XIX hasta 1910, al tiempo que discute, discretamente, la conservación de dichas representaciones utilizando los métodos de construcción de la segunda mitad del siglo XX. La visión de un esplendor pasado revelado en los bocetos elaborados por Adamo Boari se integra al fervor y la religiosidad de lgnacio Díaz Morales que encuentra en la obra un símbolo de muestra de fe. Este templo es una relación personal tanto como social e histórica. A través del mismo la ciudad encuentra una última representación de una secuencia de convulsiones del México moderno y contemporáneo al tiempo que expresa su vocación religiosa.

El proceso temporal de 70 años que tomó la construcción de este edificio conservó el estilo neogótico como base, aunque pueden encontrarse elementos arquitectónicos modernos que, relacionados con el estilo imperante, constituyen un documento visual de la evolución de pensamientos y estilos dentro del contexto de la arquitectura tapatía. Pastiche de época, recuerdo del pasado, catalizador de lo antiguo y lo moderno y espacio simbólico relevante para la ciudad, el Templo Expiatorio del Sagrado Corazón de Jesús se erige actualmente como una Summa Tapatía inseparable de la evolución de la ciudad.

\section{REFERENCIAS}

AA.W. (1974). Artes de México: Especial Guadalajara. Desarrollo Histórico de la Ciudad de Guadalajara. Edición especial 1974-1975. Revista Artes de México, 16 (I).

Checa, M. M. (2009). Hacia una geografía del Neogótico en México. Revista Esencia y Espacio. (29) 24-25.

Checa, M. (2012). Catedrales Neogóticas y Espacialidades del Poder de la Iglesia en el Occidente de México: Una Visión desde la Geografía de la Religión. Documento presentado en el XII Coloquio de Geocrítica, Bogotá, Colombia .

Celada, G. (200I). Introducción a la Suma Teológica de Santo Tomás de Aquino, en la Primera Parte de la Suma de Teología, Santo Tomás de Aquino. Recuperado de: http://biblio3.url.edu. gt/Libros/s_tomas_aquil.pdf 
De Anda, E. (2008). Historia de la Arquitectura Mexicana. México: Gustavo Gili.

De la Torre, R. (2006). Hegemonía Regional de la Diócesis de Guadalajara. La Ecclesia Nostra: El catolicismo desde la perspectiva de los laicos. El caso de Guadalajara. México: Fondo de Cultura Económica, Centro de Investigaciones y Estudios Superiores en Antropología Social.

Hernández, P. (2004). Monografías de Arquitectos de Siglo XX: Miguel Aldana Mijares. Guadalajara: Secretaría de Cultura del Gobierno de Jalisco.

Hernández, J. (200I). Guadalajara: Identidad Perdida-Prólogo. Guadalajara: Editorial Ágata.

Hurtado, F. (2010). Historicidad y devenir en los conceptos de espíritu y absoluto en Hegel. Recuperado de: http://www.saga.unal.edu.co/etexts/PDF/Ponencias20 I0/AndresHurtado.pdf

Kasis, A. (2004). Monografías de Arquitectos de Siglo XX: Ignacio Díaz Morales. Guadalajara: Secretaría de Cultura del Gobierno de Jalisco.

Mata, R. (1979). Iglesias y edificios antiguos de Guadalajara. México: Fondo de Cultura Económica.

Nagy, G. (20I 3). The Ancient Greek Hero in 24 Hours. Washington: Harvard University Press.

Secretaría de Economía. (1956). Cuadro 2. Población existente en las capitales de las entidades federativas-Años de 1877 a 1910. México: “Estadísticas Sociales del Porfiriato 1877-1910”.

Sordo, A. (1985). La Arquitectura como Proyecto de Vida. Conversación con Ignacio Días Morales. Revista Varia. Nueva Época, I3(I), 8-I5.

Víctor, M. (2015, diciembre 8). Ideal para el paseo dominical [Mensaje en Foro]. Recuperado de http://www.tripadvisor.com.mx/ShowUserReviews-g I 50798-d558549-r I 600 I6863Expiatory_Temple-Guadalajara_Guadalajara_Metropolitan_Area.htmI\#REVIEWS 